\title{
Сапон И.В.
}

Теоретико-методологические подходы к изучению протестных сообществ

Сибирский государственный университет телекоммуникаций и информатики (Россия, Новосибирск)

doi: $10.18411 / \mathrm{j}-08-2021-68$

\section{Аннотация}

В статье даётся краткий обзор основных подходов к изучению протеста. Приводится критика каждого подхода: оцениваются сильные и слабые стороны представленных концепций. Показано, что причиной протеста часто является коллективное чувство несправедливости, несоответствия реальности ожиданиям. Немаловажную роль при этом играет коллективная идентичность. Социальные движения могут структурироваться по типу формальных организаций, а также существовать в виде неформальных организаций с сетевой структурой связей.

Ключевые слова: протест, оппозиция, социальные движения, социальные сети, теория относительной депривации, теория мобилизации ресурсов, коллективная идентичность.

\section{Abstract}

The article discusses the main approaches to the study of protest, provides criticism of each of the approaches (assesses the strengths and weaknesses of the presented concepts). It is shown that the reason for the protest is often a collective sense of injustice, inconsistency of expectations and reality. Collective identity also plays an important role. At the same time, social movements can be structured according to the type of formal organizations, as well as exist in the form of informal organizations with a network structure of connections.

Keywords: protest, opposition, social movements, social networks, relative deprivation theory, resource mobilization theory, collective identity.

Серия протестов, прокатившихся по странам СНГ и зарубежья в последние десятилетия, вызвала активный интерес научного сообщества [1]. Одной из важных тем исследований стало влияние социальных интернет-сетей на организацию и координацию участников протестных движений [2]. В то же время появилось множество работ, подробно описывающих особенности протекания современных протестов в различных странах и контекстах.

Активное эмпирическое исследование реальных протестных движений должно сопровождаться прирастанием соответствующего теоретического знания. В данной работе мы проанализируем ключевые теоретические подходы к объяснению протеста, существующие в зарубежной и отечественной научной литературе.

Ушкин разделяет современную литературу по социологическому исследованию протеста на 3 категории:

1) источники, связанные с изучением реальных и виртуальных социальных сетей (особенности и тенденции в их развитии);

2) труды по теории общественных движений и протестной активности;

3) труды, посвященные влиянию социальных сетей на протестную активность населения [2].

В нашей работе мы рассмотрим вторую группу источников и опишем основные теории общественных движений, объясняющих причины и динамику протестной активности.

Двумя ключевыми теориями, активно используемыми для исследования протеста в XX веке, были: теория относительной депривации и теория мобилизации ресурсов [3]. 
Теория относительной депривации (Relative deprivation theory) усматривала причину протеста в конфликте между ожиданиями различных социальных групп, а точнее - в недовольстве одной из групп условиями своей жизни [4].

Общественные изменения могут увеличивать разрыв между уровнем ожиданий и возможностью их удовлетворения для некоторых групп населения. В таком случае у данной категории людей может возникнуть субъективное чувство недовольства по поводу экономического, социального или политического ограничения (депривации) [4].

Социальное напряжение, чувство несправедливости и неравенства могут также возникать у групп людей при сравнении своего положения с условиями жизни других. Если личная депривация возникает при сравнении индивидом своего положения с положением других индивидов, похожих на него, и выявлении несправедливости, то групповая депривация - это сравнение положения своей группы с положением других групп. Последний тип относительной депривации с гораздо большей вероятностью приведёт к протесту. Коллективное чувство несправедливости совместно с верой в возможные изменения толкает людей объединяться в протестные социальные движения.

Таким образом, данная теория разрабатывалась в ключе марксистских идей о неравенстве и строилась на описании эмоционального пути возникновения коллективных действий.

Однако, вполне возможно, что в любом обществе в той или иной степени всегда присутствует недовольство. И, вероятно, одного только его недостаточно, чтобы появилось социальное движение [5].

Согласно теории мобилизации ресурсов (Resource mobilization theory), сформировавшийся в 70-е годы в противовес теории относительной депривации, «не напряжение само по себе производит коллективное действие, а значительное увеличение организаций и ресурсов». В целом считается, что «мобилизация ресурсов требует хотя бы минимальной формы организации» [3], при этом «главная задача социального движения - использовать и мобилизовать имеющиеся ресурсы» [5].

Основные ресурсы - это деньги и рабочая сила: финансы, помещения, техническое оборудование, люди, знания, навыки, связи между людьми. Группа активистов (ядро движения) работает над тем, чтобы привлечь деньги, внимание СМИ, наладить связи с власть имущими и привлечь новых участников движения. Чем более организовано движение, тем легче ему мобилизовать ресурсы. И «чем больше мобилизационные способности социального движения, тем больше его потенциал в достижении целей по социальным изменениям» [5].

Однако данная теория имела ограничения. Например, она не учитывала фактор культуры и идентичности и не могла объяснить, как группы с ограниченными ресурсами могут добиваться своих целей.

В 80-е на смену теории мобилизации ресурсов пришли: концепция коллективной идентичности (collective identity) и теория новых общественных движений.

Согласно теории коллективной идентичности, люди признают, что они разделяют общие идеи и взгляды, и на этом основании решают действовать вместе. Данная концепция соединила структурные и индивидуально-мотивационные аспекты в анализе протестной мобилизации. Она позволила ответить на такие вопросы, как что может «объединить различные индивидуальности в сплоченную единицу, обеспечивая общую основу и групповую солидарность», как соотносятся индивидуальные мотивы и общие условия [5].

Однако не только формальные организации могут мобилизовать людей на протестные действия, но и неформальные. Теория новых общественных движений (New social movements, NSMs) показала, что протест может существовать в форме слабо организованной социальной сетевой структуры. 
Данная теория пыталась дать объяснения причинам возникновения новых протестов, которые возникли в различных западных обществах примерно с середины 1960-х годов. Утверждалось, что новые движения, распространившиеся в это время, значительно отличались в своей основе от прежних: это были не экономические или политические протесты, а, в первую очередь, социально-культурные движения за права (феминистское движение, экологическое, ЛГБТ и другие). Они касались качества жизни, индивидуальной самореализации и прав человека. Основу этих движений составлял не рабочий класс, а «новый средний класс» вместе со старым (с высоким уровнем образования и доступом к информации и ресурсам), а также люди, имеющие свободное время - студенты, домохозяйки и безработные. Социальная мобилизация происходила через культурные инновации и трансформацию идентичностей.

Однако данная теория подверглась критике за то, что различия между старыми и новыми движениями вполне могли были быть объяснены и прежними теориями. Кроме того, сами движения подобной нематериалистической направленности существовали задолго до анализируемого постиндустриального периода, а термин «новый средний класс» представлялся неоднозначным и расплывчатым.

На этом мы закончим краткий теоретический обзор. В данной работе были рассмотрены лишь самые основные подходы к изучению протеста в социальных сетях. Многие из этих теоретических идей остаются актуальными и для современных исследований социальных движений, давая основу для понимания и прогнозирования динамики происходящих в мире протестных событий.

В силу ограниченности объёмов статьи мы не затронули теорию коллективных действий (Collective action theory), теорию политических возможностей (Political opportunity theory), а также другие современные подходы, такие как: концепция рационального вылора (Rational choice theory), теория фреймов (Framing), сетевой анализ (Social network analysis), концепция умной толпы (Smart mob). Однако на наш взгляд, эти концепции также вносят немаловажный вклад в теоретическое понимание причин и динамики социального протеста.

В заключение хотелось бы сделать несколько выводов.

Причиной, толкающей людей к участию в протестном движении, является относительная депривация - чувство несоответствия ожиданий и существующей реальности, ощущение лишённости чего-то важного и ценного, того, на что протестующие, по их убеждению, имеют право. К этим чувствам может приводить экономическая, политическая, социальная и культурная депривации.

Но для того, чтобы люди мобилизовались в протестное движение, нередко требуется что-то еще. Недостаточно одного только индивидуального чувства несправедливости. Необходимо коллективное недовольство по поводу коллективной депривации, а также коллективная идентичность.

Нередко социальные движения структурируются по типу организаций, для существования которых нужны различного рода материальные и нематериальные ресурсы. Тем не менее, возможна и другая структура социальных движений - сетевая.

Исследование выполнено при финансовой поддержке РФФИ и ЭИСИ в рамках научного проекта № 21-011-32247 «Российские протестные онлайн-сообщества: характеристики и особенности»

$$
* * *
$$

1. Ушкин С. Г. Вовлеченность пользователей социальных сетей в протестное движение //Власть. 2014. №. 8. C. 138-141.

2. Ушкин С. Г. Влияние виртуальных социальных сетей на протестную активность в российском обществе : дис. - Национальный исследовательский Мордовский государственный университет им. НП Огарева, 2015. 
3. McCarthy J. D., Zald M. N. Resource mobilization and social movements: A partial theory //American journal of sociology. 1977. Vol. 82. P. 1212-1241.

4. Дементьева И. Н. Теоретико-методологические подходы к изучению социального протеста в зарубежной и отечественной науке //Мониторинг общественного мнения: экономические и социальные перемены. 2013. №. 4 С. 3-10.

5. Шульц Э. Э. Теория социальных движений: проблемы теории и практики //Вестник Северного (Арктического) федерального университета. Серия: Гуманитарные и социальные науки. 2014. №. 4. C. 23-28.

\section{Улановская И.М., Янишевская М.А. Умение учиться и образовательная программа школы}

ФГБНУ «Психологический институт» РАО (Россия, Москва)

doi: $10.18411 / \mathrm{j}-08-2021-69$

\section{Аннотация}

В статье рассматривается понятие «умение учиться», отмечается особое содержание умения учиться в начальной школе, его рефлексивная и поисковая составляющие. Описана методика диагностики рефлексивной составляющей умения учиться (авторы Г.А. Цукерман и др.). На большой выборке испытуемых показано, что традиционные образовательные программы начальной школы не оказывают эффективного влияния на формирование умения учиться у выпускников начальной школы.

Ключевые слова: умение учиться, образовательная программа, начальное школьное образование.

\section{Abstract}

The article considers the concept of "learning to learn", notes the special content of "learning to learn" in primary school, its reflexive and search components. The method of diagnostics of the reflexive component of "learning to learn" ability described (authors G. A. Zuckerman et al.). It is shown on a large sample of subjects that traditional educational programs of primary school do not have an effective impact on the formation of the "learning to learn" ability in primary school graduates.

Keywords: learning to learn, educational program, primary school education.

В последнее десятилетие во всем мире наблюдается серьезное переосмысление целей и задач школьного образования в целом и начальной школы в частности. Признается, что необходимо качественное изменение самих принципов организации образовательного процесса, его содержания, целей и задач. Поиском новых ресурсов для повышения эффективности образования в настоящее время озабочены государства с разными традициями и укладами. При этом предлагаемые модели реформирования образования имеют сходные особенности. Так, в рамках Евросоюза сформулированы общие требования к развитию национальных систем образования (European Framework of Key Competences), среди которых важнейшим универсальным навыком считается умение учиться. Для отечественной системы образования суть этих изменений связана с развитием у детей (наряду с предметными знаниями и компетенциями) обобщенных - метапредметных - способов действия и личностных компетенций. Их своеобразие подробно прописано в новых образовательных Стандартах (ФГОС НОО и ФГОС ООО 2011 года). И среди 16 метапредметных результатов, прописанных в Стандарте, первый гласит: «Метапредметные результаты освоения основной образовательной программы начального общего образования должны отражать овладение способностью принимать и сохранять цели и задачи учебной деятельности, поиска средств ее осуществления», т.е. умение учиться в самой полной и развернутой форме учебной деятельности (4). Таким образом, умение учиться должно стать основным метапредметным результатом современного образования. Умение учиться здесь понимается как способность 